\title{
Starch determination in Chlorella vulgaris-a comparison between acid and enzymatic methods
}

\author{
Bruno Fernandes • Giuliano Dragone • Ana P. Abreu • \\ Pedro Geada • José Teixeira • António Vicente
}

Received: 12 September 2011 /Revised and accepted: 12 September 2011 /Published online: 4 December 2011

(C) Springer Science+Business Media B.V. 2011

\begin{abstract}
Different methods for estimating starch in Chlorella vulgaris were compared with the view of establishing a procedure suitable for rapid and accurate determination of starch content in this microalgal species. A close agreement was observed between methods that use perchloric acid and enzymatic methods that use $\alpha$-amylase and amyloglucosidase to hydrolyze the starch of microalgae grown under different nitrogen culture conditions. Starch values obtained by these methods were significantly higher than those estimated by using hydrochloric acid as solubilizing and hydrolyzing agent. The enzymatic method (EM1) proved to be the most rapid and precise method for microalgal starch quantification. Furthermore, the evaluation of resistant starch by enzymatic methods assayed in nitrogen-sufficient and nitrogen-starved cells showed that no formation of this type of starch occurred in microalgae, meaning that this should not interfere with starch content determinations.
\end{abstract}

Keywords Amylolytic enzymes · Biofuels · Chlorella vulgaris $\cdot$ Microalgae $\cdot$ Perchloric acid $\cdot$ Starch hydrolysis

\section{Introduction}

The ongoing depletion of oil reserves coupled with economic growth and stability, and more significantly, the emerging concern about global warming arising from

\footnotetext{
B. Fernandes $\cdot$ G. Dragone $(\bowtie) \cdot$ A. P. Abreu $\cdot$ P. Geada

J. Teixeira $\cdot$ A. Vicente

IBB - Institute for Biotechnology and Bioengineering,

Centre of Biological Engineering, University of Minho,

Campus de Gualtar,

4710-057 Braga, Portugal

e-mail: gdragone@deb.uminho.pt

G. Dragone

e-mail: giulianodragone@hotmail.com
}

burning fossil fuels have become major drivers for the development of renewable and cost-effective energy sources (Stephens et al. 2010; Dragone et al. 2010). Among the different potential sources of renewable energy, liquid biofuels such as bioethanol (a petrol additive/substitute) and biodiesel (a diesel alternative) are of most interest as they are part of the few options to replace fossil fuels and have the potential to limit greenhouse gas emissions (Chen et al. 2011; Nigam and Singh 2011). However, the production of biofuels from terrestrial plants is controversial mainly due to the impact on global food markets, on food security (Brennan and Owende 2010), on arable land usage, on potable water utilization and on deforestation. In contrast, microalgae have been considered as a promising feedstock for biofuel production since they are able to convert solar energy to chemical energy via $\mathrm{CO}_{2}$ fixation and do not compete for land with crops used for food production (Ahmad et al. 2011). These photosynthetic microorganisms accumulate significant quantities of lipids and carbohydrates over short periods of time that can be subsequently processed into biofuels (Brennan and Owende 2010; Spolaore et al. 2006; Chen et al. 2009).

Certain species of microalgae such as Chlorella vulgaris have the ability to produce higher levels of starch than lipids as reserve polymer (Dragone et al. 2011). Beyond that, some strains were also found to accumulate large amounts of starch under nitrogen starvation. These species are suitable candidates for bioethanol production as starch from microalgae can be extracted to produce fermentable sugars (Mussatto et al. 2010).

Therefore, an accurate and rapid method for the determination of starch is key to the commercial success of bioethanol production from microalgae. On the other hand, some difficulties are usually encountered in choosing and implementing an appropriate methodology for microalgal starch quantification. The great number of different 
starch methods reported in the literature complicates the task of method evaluation and selection. Furthermore, variations in the accuracy of starch determination methods may confound the interpretation and comparison of results among different studies.

Methods for starch determination in microalgae can be broadly grouped into acid hydrolysis or enzymatic procedures. Examples of the former include hydrolysis with perchloric acid (Chader et al. 2009) while the latter comprises digestion with amylase and amyloglucosidase (Zemke-White and Clements 1999). Both procedures hydrolyze the starch to glucose, which is subsequently quantified colorimetrically. However, acid-based procedures might be subject to error in starch estimation due to the extraction of interfering carbohydrates from other polymers. Furthermore, enzyme digestion has been the preferred method of determining starch because, in theory, active, purified starch-degrading enzymes are specific for the hydrolysis of starch and yield highly accurate values (Rose et al. 1991).

The objective of this study was to compare different methodologies for the determination of starch in C. vulgaris, and to establish a procedure suitable for rapid and accurate routine measurement of starch content in microalgae.

\section{Materials and methods}

The freshwater microalga Chlorella vulgaris P12 kindly provided by the Algal Laboratory (CCALA), Institute of Botany, Academy of Sciences of the Czech Republic was precultivated in standard (nitrogen-sufficient) medium containing $\left(\mathrm{mg} \mathrm{L}^{-1}\right): 1100\left(\mathrm{NH}_{2}\right)_{2} \mathrm{CO}, 237 \mathrm{KH}_{2} \mathrm{PO}_{4}, 204$ $\mathrm{MgSO}_{4} \cdot 7 \mathrm{H}_{2} \mathrm{O}, 40 \mathrm{FeNa}-\mathrm{C}_{10} \mathrm{H}_{12} \mathrm{O}_{8} \mathrm{~N}_{2}, 88 \mathrm{CaCl}_{2}, 0.83$ $\mathrm{H}_{3} \mathrm{BO}_{3}, 0.95 \mathrm{CuSO}_{4} \cdot 5 \mathrm{H}_{2} \mathrm{O}, 3.3 \mathrm{MnCl}_{2} \cdot 4 \mathrm{H}_{2} \mathrm{O}, 0.17$ $\left(\mathrm{NH}_{4}\right)_{6} \mathrm{Mo}_{7} \mathrm{O}_{24} \cdot 4 \mathrm{H}_{2} \mathrm{O}, 2.7 \mathrm{ZnSO}_{4} \cdot 7 \mathrm{H}_{2} \mathrm{O}, 0.6 \mathrm{CoSO}_{4} \cdot 7 \mathrm{H}_{2} \mathrm{O}$,
$0.014\left(\mathrm{NH}_{4}\right) \mathrm{VO}_{3}$ in distilled water (Fernandes et al. 2010). Cells in the late exponential growth phase were centrifuged at $8,750 \times \mathrm{g}$ for $15 \mathrm{~min}$, washed in distilled water and resuspended in nitrogen-sufficient and nitrogen-starved (standard medium without urea) culture media. Photoautotrophic cultivation of $C$. vulgaris was performed at $30^{\circ} \mathrm{C}$ in $1 \mathrm{~L}$ photobioreactors containing $400 \mathrm{~mL}$ of medium with a surface irradiance of $70 \mu \mathrm{mol}$ photons $\mathrm{m}^{-2} \mathrm{~s}^{-1}$ provided by four fluorescent lamps (Sylvania Standard F18W). All cultures were agitated using air enriched with $2 \%(\mathrm{v} / \mathrm{v}) \mathrm{CO}_{2}$ at an aeration rate of $0.833 \mathrm{vvm}$ (volume of gas per volume of culture suspension per minute).

Methods for starch determination

Microalgal cells at the beginning of the stationary growth phase were harvested by centrifugation at $8,750 \times g$ for $15 \mathrm{~min}$, washed in distilled water, lyophilized and disintegrated $(10 \mathrm{mg})$ with a mortar and pestle prior to starch analysis. The disintegration of the cells was performed for $5 \mathrm{~min}$, monitored through microscopic observation. Cells were removed from the mortar and pestle using solvents (ethanol solution or acetone, depending on the method).

Starch content was expressed as \% w/w (dry weight basis). The different methods for determination of microalgal starch compared in this study are summarized in Table 1.

Perchloric acid method (AM1)

In this method (Rose et al. 1991), the cells were first extracted with acetone and subsequently extracted with boiling $80 \%(\mathrm{v} / \mathrm{v})$ ethanol until the extract remained colorless, in order to remove interfering substances (e.g., pigments, soluble sugars and lipids) and to gelatinize starch granules. The removal of interfering substances is extreme-

Table 1 Comparison of reagents and estimated time employed in the determination of microalgal starch concentration by acid and enzymatic methods

\begin{tabular}{|c|c|c|c|c|}
\hline \multirow[t]{2}{*}{ Step } & \multicolumn{4}{|l|}{ Method } \\
\hline & AM1 & AM2 & AM3 & EM1/EM2 \\
\hline \multirow[t]{3}{*}{ Removal of interfering substances } & Acetone & & Acetone & \\
\hline & $80 \%$ ethanol & $80 \%$ ethanol & $80 \%$ ethanol & $80 \%$ ethanol \\
\hline & $8 \mathrm{~h}$ & $1 \mathrm{~h}$ & $2 \mathrm{~h}$ & $0.5 \mathrm{~h}$ \\
\hline \multirow[t]{3}{*}{ Starch extraction and solubilization } & $35 \% \mathrm{HClO}_{4}$ & $30 \% \mathrm{HClO}_{4}$ & $1.1 \% \mathrm{HCl}$ & $\alpha$-Amylase \\
\hline & & & & Amyloglucosidase \\
\hline & $0.5 \mathrm{~h}$ & $1 \mathrm{~h}$ & $0.5 \mathrm{~h}$ & $1 \mathrm{~h}$ \\
\hline \multirow[t]{2}{*}{ Colorimetric determinationof glucose } & Anthrone & Anthrone & Anthrone & Glucose oxidase + peroxidase \\
\hline & $0.5 \mathrm{~h}$ & $0.5 \mathrm{~h}$ & $0.5 \mathrm{~h}$ & 0.75 \\
\hline Total time & $9.0 \mathrm{~h}$ & $2.5 \mathrm{~h}$ & $3.0 \mathrm{~h}$ & $2.25 \mathrm{~h}$ \\
\hline
\end{tabular}

AM1 perchloric acid method (Rose et al. 1991), AM2 modified perchloric acid method (Brányiková et al. 2011), AM3 hydrochloric acid method (Oren et al. 1988), EM1 enzymatic method (Megazyme 2009), EM2 enzymatic method for resistant starch (Megazyme 2009) 
ly important since they are able to react colorimetrically, thus leading to the overestimation of starch values.

Subsequently, the microalgal starch was extracted and solubilized with $35 \%(\mathrm{v} / \mathrm{v})$ perchloric acid. The solubilized starch solution was then reacted with a mixture of concentrated sulfuric acid and anthrone $(2 \mathrm{~g}$ anthrone in $1 \mathrm{~L}$ of $72 \%(\mathrm{v} / \mathrm{v})$ $\mathrm{H}_{2} \mathrm{SO}_{4}$ ) to quantify glucose spectrophotometrically at $625 \mathrm{~nm}$.

Modified perchloric acid method (AM2)

In this method (Brányiková et al. 2011), the removal of interfering substances using acetone was avoided, and the duration of this and subsequent (starch extraction and solubilization) steps was shortened, when compared with AM1 (Table 1). Pigments were extracted three times using $80 \%$ ethanol for $15 \mathrm{~min}$ at $68^{\circ} \mathrm{C}$. For total hydrolysis of starch, 30\% perchloric acid was added to the sediment, stirred for $15 \mathrm{~min}$ at $25^{\circ} \mathrm{C}$ and centrifuged. This procedure was repeated three times. The solubilized starch solution was then reacted with a mixture of concentrated sulfuric acid and anthrone as described for AM1.

\section{Hydrochloric acid method (AM3)}

The microalgal biomass was extracted with acetone and boiling $80 \%(\mathrm{v} / \mathrm{v})$ ethanol as described in the AM1 method aiming at the removal of interfering substances. Subsequently, starch granules were hydrolyzed with $1.1 \%$ hydrochloric acid at $100^{\circ} \mathrm{C}$ for $30 \mathrm{~min}$ (Oren et al. 1988). Glucose was determined colorimetrically by the anthrone reaction after starch hydrolysis.

\section{Enzymatic method (EM1)}

The starch content of $C$. vulgaris was assayed by enzymatic degradation of the starch to glucose with $\alpha$-amylase and amyloglucosidase, using the total starch assay procedure from Megazyme (Megazyme 2009) accepted by AOAC-Association of Analytical Communities (Official Method 996.11) and AACC-American Association of Cereal Chemists (Method 76.13). Lyophilized microalgal biomass, previously disintegrated, was resuspended in $80 \%(\mathrm{v} / \mathrm{v})$ ethanol and incubated in a water bath at $80-85^{\circ} \mathrm{C}$ for $5 \mathrm{~min}$, in order to extract interfering compounds. Thermostable $\alpha$-amylase $\left(3,000 \mathrm{U} \mathrm{mL}^{-1}\right)$ in MOPS buffer $(50 \mathrm{mM}, \mathrm{pH} 7.0)$ containing $5 \mathrm{mM} \mathrm{CaCl}_{2}$, was added to each sample. The samples were incubated in a boiling water bath for $6 \mathrm{~min}$, with mixing at 2 min intervals, and then placed in a block heater at $50^{\circ} \mathrm{C}$ and allowed to equilibrate for $5 \mathrm{~min}$. Amyloglucosidase $\left(3,300 \mathrm{U} \mathrm{mL}^{-1}\right)$ in sodium acetate buffer $(200 \mathrm{mM}, \mathrm{pH} 4.5)$ plus sodium azide $(0.02 \% \mathrm{w} / \mathrm{v})$ was subsequently added to each sample. After that, samples were incubated at $50^{\circ} \mathrm{C}$ for $30 \mathrm{~min}$, and centrifuged for $10 \mathrm{~min}$ at $4,500 \times \mathrm{g}$ to separate any remaining insoluble material. Aliquots of the supernatant were assayed for glucose. Each aliquot was added to $3.0 \mathrm{~mL}$ of GOPOD reagent in distilled water. This reagent contained, according to the manufacturer's specifications: glucose oxidase $(>12,000 \mathrm{U})$; peroxidase $(>650 \mathrm{U})$ and 4-aminoantipyrine ( $80 \mathrm{mg}$ ). Samples were incubated at $50^{\circ} \mathrm{C}$ for $20 \mathrm{~min}$ and then cooled to room temperature. The absorbance of samples and the D-glucose control were measured at $510 \mathrm{~nm}$ in a spectrophotometer against a reagent blank solution consisting of $0.1 \mathrm{~mL}$ of water and $3.0 \mathrm{~mL}$ of GOPOD reagent.

Enzymatic method for resistant starch (EM2)

The enzymatic method for resistant starch proposed by Megazyme (Megazyme 2009) was based on the EM1 method detailed above, except that after extraction of interfering compounds with hot ethanol, the microalgal biomass was predissolved with $2 \mathrm{M} \mathrm{KOH}$ in an ice/water bath, followed by neutralization with sodium acetate buffer and further hydrolysis with $\alpha$-amylase and amyloglucosidase.

Statistical design and analysis

Each of the five methods was tested in triplicate on the microalgal biomass. The replicates were performed using cells from two cultivations, one under nitrogen sufficient and another under nitrogen starved conditions. The accuracy of each method was evaluated as the percentage relative error $(\% \mathrm{Er})$ between their mean results and those obtained by the official method EM1 according to the equation given below (Eq. 1).

$\% \mathrm{Er}=100 *\left(C_{\mathrm{M}}-C_{\mathrm{OF}}\right) / C_{\mathrm{OF}}$

where $C_{\mathrm{M}}=$ mean starch concentration measured by a specific method and $C_{\mathrm{OF}}=$ mean starch content obtained by the official enzymatic method EM1. The precision of each method was obtained by determining the percentage relative standard deviation (\%RSD) according to Eq. 2.

$\% \mathrm{RSD}=100 * s / C_{\mathrm{M}}$

where $s=$ standard deviation and $C_{\mathrm{M}}=$ mean starch concentration measured by a specific method. Results were analyzed by the Experimental Design Module of the Statistica 8.0 software (Statsoft, USA).

\section{Results and discussion}

Comparison of starch content in C. vulgaris determined by acid and enzymatic methods

Figure 1 shows the comparison of different methods for determining the starch content in microalgae cultivated 


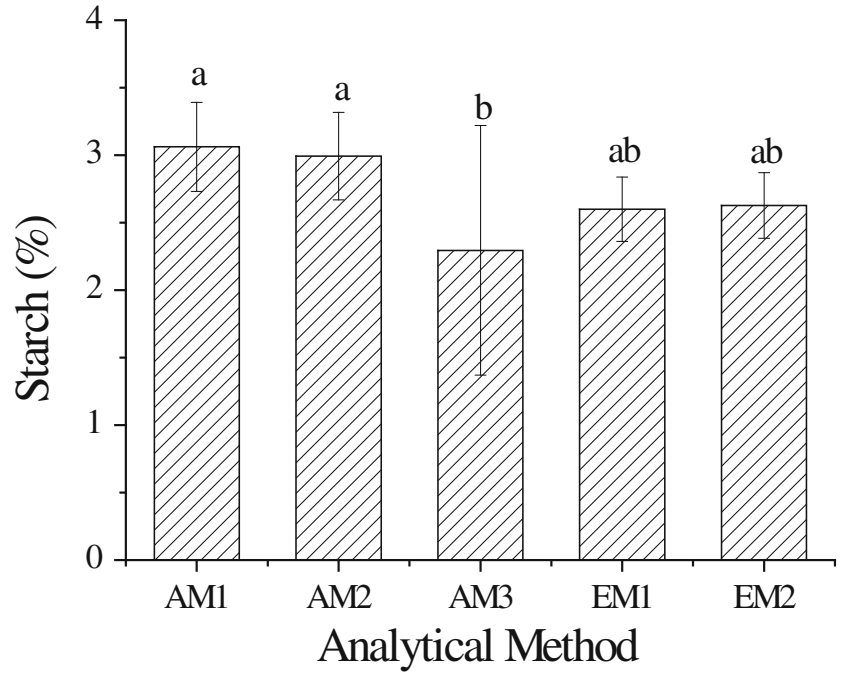

Fig. 1 Starch concentration (mean of three replicates \pm standard deviation) in $C$. vulgaris grown under nitrogen sufficient conditions. Columns with the same letters are not significantly different $(p<0.05)$ according to the Tukey's test for mean comparisons. (AM1 perchloric acid method (Rose et al. 1991), AM2 modified perchloric acid method (Brányiková et al. 2011), AM3 hydrochloric acid method (Oren et al. 1988), EM1 enzymatic method (Megazyme 2009), EM2 enzymatic method for resistant starch (Megazyme 2009))

under nitrogen sufficient conditions. It can be observed that there was no statistically significant difference $(p<0.05)$ between the starch content of $C$. vulgaris determined either by perchloric acid methods (AM1 and AM2) and enzymatic methods (EM1 and EM2).

On the other hand, the hydrochloric acid method (AM3) provided nearly $20 \%$ lower estimates of starch content than those obtained by perchloric acid methods (AM1 and AM2). These results may be attributed to the higher efficiency of starch extraction and hydrolysis with $\mathrm{HClO}_{4}$ in comparison with $\mathrm{HCl}$. According to Raessler et al. (2010), the accurate determination of starch is dependent on both its complete extraction from the sample and its complete hydrolysis into glucose. In green algae, starch is synthesized and stored within the chloroplast, which considerably limits the accessibility of the solvent during extraction. Consequently, extraction of starch generally needs rather harsh conditions to allow thorough access of the solvent. A previous study (Fontana et al. 2001) reported that the higher the acid strength, the higher the yield of glucose released from starch by acid hydrolysis. As a result, the higher starch values obtained by the perchloric acid method can be related to the greater acid strength of $\mathrm{HClO}_{4}$ compared to that of $\mathrm{HCl}$. In this sense, perchloric acid has been considered to be the most efficient solvent for starch extraction from plant tissues (Ghiena et al. 1993).

Starch content of C. vulgaris estimated by the hydrochloric acid method was also significantly lower than those obtained by both perchloric acid methods at the end of microalgae cultivation under nitrogen starvation conditions (Fig. 2). As can be seen in Fig. 2, the specific starch concentration in nitrogen-depleted microalgae reached $30 \%$ as determined by the hydrochloric acid method, while the estimation of the microalgal starch content attained 33.5\% and $35 \%$ according to AM1 and AM2 methods, respectively, which use $\mathrm{HClO}_{4}$ as a solubilizing and hydrolyzing agent. The significant differences among the starch values obtained by both acid methods may be related to the difference in acid strengths between $\mathrm{HClO}_{4}$ and $\mathrm{HCl}$, as explained above.

Figure 2 also shows that enzymatic methods yielded significantly higher microalgal starch concentrations than that obtained by the hydrochloric acid method. On the other hand, the starch values estimated by using amylolytic enzymes did not differ significantly (at a $95 \%$ confidence level) from those resulting from perchloric acid methods.

Table 2 summarizes the precision and accuracy of the tested methods for the determination of starch in microalgae cultivated under nitrogen sufficient conditions. According to this table, the accuracy of AM2 method was similar to that of the perchloric acid method AM1 for the estimation of the microalgal starch content. Moreover, it can be observed in Table 2 that precisions $(10.8 \%)$ achieved by both perchloric acid methods were comparable to that obtained by the enzymatic method EM1 (9.2\%).

Although the perchloric acid method AM2 provided a higher relative error (lower accuracy) than method AM1

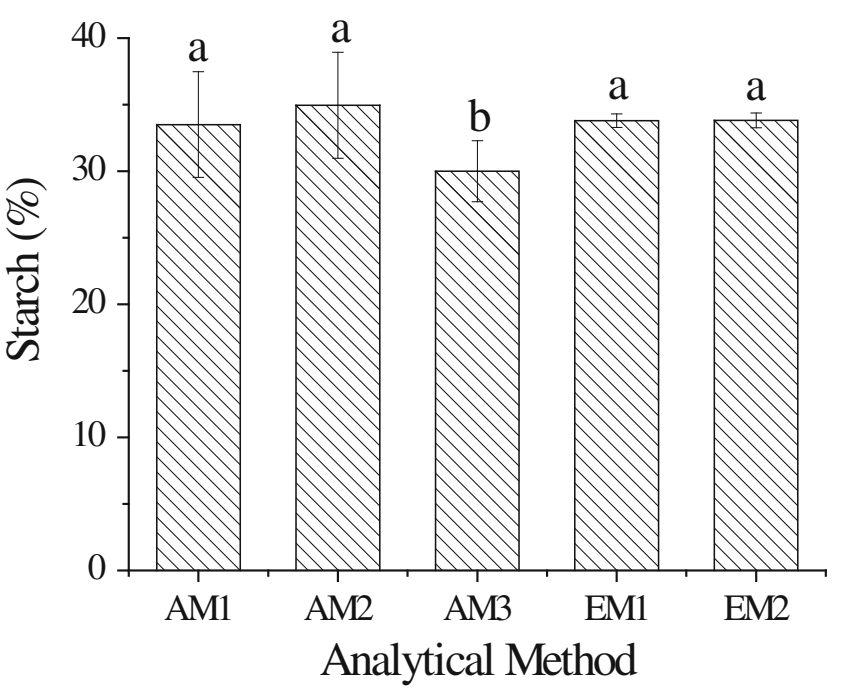

Fig. 2 Starch concentration (mean of three replicates \pm standard deviation) in C. vulgaris grown under nitrogen starvation conditions. Columns with the same letters are not significantly different $(p<0.05)$ according to the Tukey's test for mean comparisons. (AMI perchloric acid method (Rose et al. 1991), AM2 modified perchloric acid method (Brányiková et al. 2011), AM3 hydrochloric acid method (Oren et al. 1988), EM1 enzymatic method (Megazyme 2009), EM2 enzymatic method for resistant starch (Megazyme 2009)) 
Table 2 Comparison of accuracy and precision of methods for estimating starch content in nitrogen-sufficient microalgae

\begin{tabular}{lcc}
\hline Method & Accuracy (\%) & Precision (\%) \\
\hline AM1 & 17.8 & 10.8 \\
AM2 & 15.1 & 10.8 \\
AM3 & -11.7 & 40.3 \\
EM1 & - & 9.2 \\
EM2 & 1.1 & 9.3 \\
\hline
\end{tabular}

AM1 perchloric acid method (Rose et al. 1991), AM2 modified perchloric acid method (Brányiková et al. 2011), AM3 hydrochloric acid method (Oren et al. 1988), EMI enzymatic method (Megazyme 2009), EM2 enzymatic method for resistant starch (Megazyme 2009)

(3.4 and 0.9, respectively) for determining starch concentration in nitrogen-starved cultures of C. vulgaris (Table 3), starch values estimated by both perchloric acid methods did not differ significantly from that obtained by the enzymatic method EM1 (Fig. 2). Additionally, both perchloric acid methods yielded similar precisions to that reported for the determination of starch in microalgae cultivated under nitrogen sufficient conditions (Table 2).

By comparing Tables 2 and 3, it can also be noticed that methods AM1 and AM2 provided a more accurate value of the starch content in nitrogen-starved cells than that estimated in cells grown under nitrogen-sufficient conditions. This result may be due to the lower concentration of interfering compounds (e.g., proteins) present in microalgae grown under nitrogen starvation conditions. It has been reported (Esposito et al. 2006) that the protein content in green microalgae is about threefold higher in nitrogensufficient cells with respect to nitrogen-starved cells. According to Chow and Landhäusser (2004), watersoluble compounds such as proteins react with the concentrated sulfuric acid in the glucose assay and, therefore, significantly interfere with the absorbance reading. Tables 2 and 3 also show that the enzymatic method EM1 had the best precision in starch quantification, while

Table 3 Comparison of accuracy and precision of methods for estimating starch content in nitrogen-starved microalgae

\begin{tabular}{lcc}
\hline Method & Accuracy (\%) & Precision (\%) \\
\hline AM1 & -0.9 & 11.8 \\
AM2 & 3.4 & 11.4 \\
AM3 & -11.2 & 7.7 \\
EM1 & - & 1.5 \\
EM2 & 0.1 & 1.7
\end{tabular}

AM1 perchloric acid method (Rose et al. 1991), AM2 modified perchloric acid method (Brányiková et al. 2011), AM3 hydrochloric acid method (Oren et al. 1988), EMI enzymatic method (Megazyme 2009), EM2 enzymatic method for resistant starch (Megazyme 2009) method AM3 yielded the highest percentage relative standard deviation.

Evaluation of resistant starch in C. vulgaris

Many of the properties of starches including gelatinisation characteristics, solubility, and the formation of resistant starch determine their suitability for particular applications (Maršálková et al. 2010). By definition, resistant starch is the portion of starch that resists hydrolysis by amylolytic enzymes in the small intestine. It is a linear molecule of $\alpha$ 1,4-D-glucan, essentially derived from the retrograded amylose fraction, and has a relatively low molecular weight $\left(1.2 \times 10^{5} \mathrm{Da}\right)$ (Fuentes-Zaragoza et al. 2010). Resistant starch formation depends on several factors such as physical structure of starch, possible cross-linking/structural modification of starch and protein-starch/lipid-starch interactions (Tharanathan and Mahadevamma 2003).

In our study, formation of resistant starch in C. vulgaris was evaluated by comparing starch contents determined either by the enzymatic method EM1 for nonresistant starch and the enzymatic method for samples containing resistant starch (EM2). According to Figs. 1 and 2, no statistically significant differences were found between the starch values determined by both enzymatic methods at the end of the cultivation period under nitrogen sufficient and nitrogen starvation conditions, respectively. These findings led us to hypothesize that formation of resistant starch did not occur under either growing condition.

\section{Conclusions}

We conclude that perchloric acid methods and enzymatic methods gave similar values for the concentrations of starch in C. vulgaris grown under different nitrogen conditions. On the other hand, hydrochloric acid method resulted in significantly lower estimates of starch in microalgae. The enzymatic method EM1 that uses $\alpha$-amylase and amyloglucosidase to hydrolyze the starch of microalgae proved to be the most rapid and precise procedure for starch determination in $C$. vulgaris.

By comparing the enzymatic method for nonresistant starch and the enzymatic method for samples containing resistant starch, we concluded that no resistant starch was formed in microalgae cultivated neither under nitrogen sufficient nor nitrogen starvation conditions.

Acknowledgement This research work was supported by the grants SFRH/BD/44724/2008 (Bruno Fernandes) from Fundação para a Ciência e a Tecnologia (Portugal) and SFRH/BPD/44935/2008 (Giuliano Dragone). The authors also acknowledge the financial support received through the projects INNOVALGAE (FCT PTDC/ AAC-AMB/108511/2008) and ALGANOL. 


\section{References}

Ahmad AL, Yasin NHM, Derek CJC, Lim JK (2011) Microalgae as a sustainable energy source for biodiesel production: a review. Renew Sust Energ Rev 15:584-593

Brányiková I, Maršálková $\mathrm{B}$, Doucha $\mathrm{J}$, Brányik T, Bišová $\mathrm{K}$, Zachleder V, Vítová M (2011) Microalgae-novel highly efficient starch producers. Biotechnol Bioeng 108:766-776

Brennan L, Owende P (2010) Biofuels from microalgae - a review of technologies for production, processing, and extractions of biofuels and co-products. Renew Sust Energ Rev 14:557-577

Chader S, Hacene H, Agathos SN (2009) Study of hydrogen production by three strains of Chlorella isolated from the soil in the Algerian Sahara. Int J Hydrogen Energ 34:4941-4946

Chen W, Zhang C, Song L, Sommerfeld M, Hu Q (2009) A high throughput Nile Red method for quantitative measurement of neutral lipids in microalgae. J Microbiol Meth 77:41-47

Chen C-Y, Yeh K-L, Aisyah R, Lee D-J, Chang J-S (2011) Cultivation, photobioreactor design and harvesting of microalgae for biodiesel production: a critical review. Bioresource Technol 102:71-81

Chow PS, Landhäusser SM (2004) A method for routine measurements of total sugar and starch content in woody plant tissues. Tree Physiol 24:1129-1136

Dragone G, Fernandes B, Vicente A, Teixeira JA (2010) Third generation biofuels from microalgae. In: Vilas AM (ed) Current research, technology and education topics in applied microbiology and microbial biotechnology, vol 2. Formatex Research Center, Badajoz, pp 1355-1366

Dragone G, Fernandes BD, Abreu AP, Vicente AA, Teixeira JA (2011) Nutrient limitation as a strategy for increasing starch accumulation in microalgae. Appl Energ 88:3331-3335

Esposito S, Guerriero G, Vona V, Di Martino RV, Carfagna S, Rigano C (2006) Glucose-6P dehydrogenase in Chlorella sorokiniana (211/8 k): an enzyme with unusual characteristics. Planta 223:796-804

Fernandes B, Dragone G, Teixeira J, Vicente A (2010) Light regime characterization in an airlift photobioreactor for production of microalgae with high starch content. Appl Biochem Biotechnol 161:218-226

Fontana J, Passos M, Baron M, Mendes S, Ramos L (2001) Cassava starch maltodextrinization/monomerization through thermopres- surized aqueous phosphoric acid hydrolysis. Appl Biochem Biotechnol 91-93:469-478

Fuentes-Zaragoza E, Riquelme-Navarrete MJ, Sánchez-Zapata E, Pérez-Álvarez JA (2010) Resistant starch as functional ingredient: a review. Food Res Int 43:931-942

Ghiena C, Schulz M, Schnabl H (1993) Starch degradation and distribution of the starch-degrading enzymes in Vicia faba leaves (diurnal oscillation of amylolytic activity and starch content in chloroplasts). Plant Physiol 101:73-79

Maršálková $B$, Širmerová $M$, Kuřec $M$, Brányik T, Brányiková I, Melzoch K, Zachleder V (2010) Microalgae Chlorella sp. as an alternative source of fermentable sugars. Chem Eng Trans $21: 1279-1284$

Megazyme (2009) Total starch assay procedure (amyloglucosidase/ $\alpha$ amylase method). Megazyme International Ireland Ltd., Wicklow, Ireland

Mussatto SI, Dragone G, Guimarães PMR, Silva JPA, Carneiro LM, Roberto IC, Vicente A, Domingues L, Teixeira JA (2010) Technological trends, global market, and challenges of bioethanol production. Biotechnol Adv 28:817-830

Nigam PS, Singh A (2011) Production of liquid biofuels from renewable resources. Prog Energ Combust 37:52-68

Oren R, Schulze ED, Werk KS, Meyer J, Schneider BU, Heilmeier H (1988) Performance of two Picea abies (L.) Karst. stands at different stages of decline. Oecologia 75:25-37

Raessler M, Wissuwa B, Breul A, Unger W, Grimm T (2010) Chromatographic analysis of major non-structural carbohydrates in several wood species - an analytical approach for higher accuracy of data. Anal Method 2:532-538

Rose R, Rose CL, Omi SK, Forry KR, Durall DM, Bigg WL (1991) Starch determination by perchloric acid vs enzymes: evaluating the accuracy and precision of six colorimetric methods. J Agr Food Chem 39:2-11

Spolaore P, Joannis-Cassan C, Duran E, Isambert A (2006) Commercial applications of microalgae. J Biosci Bioeng 101:87-96

Stephens E, Ross IL, Mussgnug JH, Wagner LD, Borowitzka MA, Posten C, Kruse O, Hankamer B (2010) Future prospects of microalgal biofuel production systems. Trends Plant Sci 15:554-564

Tharanathan RN, Mahadevamma S (2003) Grain legumes-a boon to human nutrition. Trends Food Sci Tech 14:507-518

Zemke-White WL, Clements KD (1999) Chlorophyte and rhodophyte starches as factors in diet choice by marine herbivorous fish. J Exp Mar Biol Ecol 240:137-149 